Original Article

\title{
Changes in Glucose, TNF- $\alpha$ and IL-6 Blood Levels in Middle-aged Women Associated with Aerobic Exercise and Meditation Training
}

\author{
Sun Hur, PhD ${ }^{1)}$, Gun-Soo Han, PhD ${ }^{2)}$, Byung-Jun Cho, PhD ${ }^{3)^{*}}$ \\ 1) Division of Sport Science, Kangwon National University, Republic of Korea \\ 2) Department of Sports and Leisure Studies, College of Humanity, Daegu University, Republic of \\ Korea \\ 3) Department of Emergency Medical Technology, Kangwon National University: Kuydong Samcheok \\ City, Kangwondo 245-711, Republic of Korea
}

\begin{abstract}
Purpose] The purpose of this study was to investigate the effects of exercise therapy on glucose, TNF- $\alpha$ and IL- 6 blood levels in middle-aged women. [Subjects] A total of 46 participants were assigned to four groups: Type D personality+Exercise $(n=12)$, Type $\mathrm{D}+$ no-Exercise $(n=12)$, not-Type $\mathrm{D}+$ Exercise $(n=12)$, and notType D+no-Exercise $(n=10)$. [Methods] Blood glucose was measured by the hexokinase method. An enzyme-linked immunosorbent assay (ELISA) was used to measure the circulating plasma levels of TNF- $\alpha$ and IL-6 (Quantikine HS, R\&D Systems, Minneapolis, USA). An aerobic exercise program and meditation were conducted in parallel by the Exercise groups for 10 months. Stretching was performed for $10 \mathrm{~min}$ as a warm-up, and then walking and running on a treadmill at 60 to $70 \%$ of HRmax were performed for 40 min three times a week. Blood samples were processed according to standard laboratory procedures. [Results] Fasting glucose showed a significant interaction effect among groups, group $\times$ time, and post-test. TNF- $\alpha$ showed a significant difference among groups, and was lower in the not-Type D personality+Exercise group than in the other three groups. IL-6 showed a significant difference among the groups. [Conclusion] In conclusion, personality may affect the established effect of exercise on cytokine activity. Type D personality was independently associated with significant immune activation, and increase in TNF- $\alpha$ activity was observed among Type D participants.

Key words: Glucose, TNF- $\alpha$, IL-6 blood levels
\end{abstract}

(This article was submitted May 7, 2014, and was accepted Jun. 17, 2014)

\section{INTRODUCTION}

Negative emotions are associated with increased production of pro-inflammatory cytokines including tumor necrosis factor-alpha (TNF- $\alpha$ ) and interleukin-6 (IL-6) ${ }^{1,2)}$. Episodic psychological risk factors such as depression have been associated with poor prognosis in cardiovascular disease $(\mathrm{CVD})^{3,4)}$. Chronic psychological risk factors may also affect the clinical manifestations of heart disease ${ }^{5)}$, but individual differences in personality traits have received little attention to date in behavioral immunology research ${ }^{6,7)}$. Type $\mathrm{D}$ personality has been associated with increased levels of inflammatory biomarkers ${ }^{8-11)}$ and unfavorable cytokine profiles ${ }^{11)}$ in CVD. Preliminary findings for a group of 42 male patients with chronic heart failure (CHF) suggested that Type D personality was associated with the activated immune system characteristic of heart failure syndrome ${ }^{9)}$.

*Corresponding author. Byung-Jun Cho (E-mail: cho6451@ kangwon.ac.kr)

(C2014 The Society of Physical Therapy Science. Published by IPEC Inc. This is an open-access article distributed under the terms of the Creative Commons Attribution Non-Commercial No Derivatives (by-ncnd) License $<$ http://creativecommons.org/licenses/by-nc-nd/3.0/>.
The study revealed that, circulating levels of the pro-inflammatory cytokine TNF- $\alpha$ were significantly higher in Type D patients than in not-Type D patients ${ }^{9}$. . Type D personality was also independently associated with increased circulating levels of TNF- $\alpha$ in a subsequent study of CHF patients ${ }^{8)}$. We hypothesized that Type D personality is independently related to immune activation in patients with $\mathrm{CHF}$ and severely depressed left ventricular function ${ }^{8}$. Few studies have investigated whether Type D personality is a physiological factor deciding cytokine concentration increases in CVD. Pro-inflammatory cytokines indicate potential onset of disease in CVD symptom-free people and physical activity or exercise can lower the potential risk levels of $\mathrm{CVD}^{12)}$.

Regular aerobic exercise reduces CVD risk factors and levels of oxidative stress, and has a positive influence on lipoprotein metabolism ${ }^{13)}$. Also it is reported that meditation increases the nitrogen oxide, a strong vasodilator, level in the body and improves cardiovascular functioning and $\operatorname{arteriosclerosis}^{14)}$.

Therefore, the aim of this study was to search for an association of Type D personality with pro-inflammatory cytokine levels, through comparison of the pro-inflammatory cytokine levels of middle-aged women who performed an exercise intervention. 


\section{SUBJECTS AND METHODS}

A total of 46 middle aged women participated in this study. The characteristics of the participants are shown in Table 1. All subjects participated voluntarily and gave their written informed consent. The participants were allocated to one of the following four groups: Type D personality+Exercise $(n=12)$, Type $\mathrm{D}+$ no-Exercise $(n=12)$, not-Type $\mathrm{D}+$ Exercise $(n=12)$, and not-Type $\mathrm{D}+$ no-Exercise $(n=10)$. All participants completed the 14-item Type D Scale (DS14) to assess whether or not they had a Type D personality. The DS14 consists of two subscales, negative affectivity (NA) and social inhibition (SI), both of which comprise 7 items. A standardized cutoff score $\geq 10$ on both subscales is used to classify a person as having a Type D personality. In this study, a Korean version of the DS14 developed by Lim et al. was used ${ }^{15}$. Cronbach's alpha is 0.82 for the NA subscale and 0.80 for the SI subscale. Subjects who reported going through menopause, drinking, smoking, and performing regular exercise in the past 6 months were excluded from this study. The sample size of this study was estimated prior to data collection by using a power analysis method as previously suggested ${ }^{16)}$. Assuming a medium effect size of 0.25 and an alpha level of $0.05, G^{*}$ Power 3.1 estimated that at least 8 participants would be necessary. All experiments were reviewed and approved by the Committee of the Kangwon National University. Blood samples were collected following a 12-hour overnight fast. Samples were processed according to standard laboratory procedures. They were processed under the same conditions before exercise and 10 months after exercise. Blood glucose was measured by the hexokinase method ${ }^{17)}$. An enzyme-linked immunosorbent assay (ELISA) was used to measure circulating plasma levels of TNF- $\alpha$ and IL-6 (Quantikine HS, R\&D Systems, Minneapolis, USA). An aerobic exercise program and meditation were performed by the Exercise groups three times a week for 10 months. The aerobic exercise program consisted of three parts: a warm-up, walking and running, and cool-down. Before starting walking and running on a treadmill, all the subjects performed stretching for $10 \mathrm{~min}$. This was followed by walking and running on a treadmill at 60 to $70 \%$ of HRmax ${ }^{13,18)}$ for $40 \mathrm{~min}$. In order to accurately check whether the exercise was conducted within the set range of exercise intensity, we monitored the heart rated of the subjects with a wearable automatic portable heart rate meter (Polar Electro, Kempele, Finland). The meditation was performed for 20 minutes. The subjects were asked to sit in the pyramid sitting position and to concentrate on breathing only; therefore, the subjects took only deep breaths using their diaphragm rather than short, shallow breaths from their chest until they felt calm. The ratio of inspiration to expiration breathing began at 1:1 and the ratio was increased to 1:2.

Data are presented as means \pm standard deviation (SD). Two-way repeated measures ANOVA was performed to examine differences between Type D personality and notType D. When a significant interaction effect was found between main effects, the paired t-test was performed to compare the effects between groups by time. For compari-
Table 1. Characteristics of the subjects

\begin{tabular}{lllr}
\hline Variables & Groups & & $\mathrm{M} \pm \mathrm{S}$ \\
\hline & Type D & Exercise & $47.83 \pm 1.75$ \\
Age & & No-Exercise & $47.58 \pm 2.50$ \\
(years) & Not-Type D & Exercise & $46.58 \pm 2.43$ \\
& & No-Exercise & $46.73 \pm 1.90$ \\
& \multirow{2}{*}{ Type D } & Exercise & $156.55 \pm 4.93$ \\
Height & & No-Exercise & $157.19 \pm 4.74$ \\
$(\mathrm{~cm})$ & Not-Type D & Exercise & $157.28 \pm 6.16$ \\
& & No-Exercise & $157.86 \pm 5.31$ \\
& \multirow{2}{*}{ Type D } & Exercise & $69.21 \pm 9.99$ \\
Weight & & No-Exercise & $66.81 \pm 8.00$ \\
$($ kg) & \multirow{2}{*}{ Not-Type D } & Exercise & $66.43 \pm 4.00$ \\
& & No-Exercise & $66.89 \pm 3.73$ \\
\hline
\end{tabular}

son of groups by time, one-way ANOVA and Duncan's post hoc test were performed. SPSS for Windows version 20.0 was used for the statistical analysis, and values of $p<0.05$ were considered statistically significant.

\section{RESULTS}

The changes in glucose and pro-inflammatory cytokines after 10 months of exercise are shown in Table 2 . The fasting glucose showed a significant interaction effect among the groups $(p<0.001)$, and group $\times$ time $(p=0.034)$, and post hoc test results. The values of the Type D groups were significantly higher than those of the not-Type D groups. The TNF- $\alpha$ levels showed significant differences among the groups $(\mathrm{p}=0.015)$, and that of the not-Type $\mathrm{D}+$ Exercise group was lower than those of the other three groups. The IL-6 levels showed significant differences among the groups $(\mathrm{p}=0.014)$, and times $(\mathrm{p}=0.044)$, and was significantly lower in the Exercise groups than in the no-Exercise groups.

\section{DISCUSSION}

TNF- $\alpha$ and IL- 6 blood levels of obesity or diabetic patients are significantly higher than those of normal subjects ${ }^{19)}$. Excessive accumulation of body fat due to obesity and overweight increases blood cytokine levels such as those of TNF- $\alpha$ and IL-6. Ultimately, this increase causes insulin degradation of the liver and skeletal muscle, and increases the risk levels of various degenerative disorders including metabolic syndrome and insulin resistance ${ }^{9,12)}$. TNF- $\alpha$ and IL- 6 have been shown to be implicated in the pathogenesis of $\mathrm{CVD}^{20)}$. IL-6 stimulates the production of C-reactive protein and fibrinogen ${ }^{6}$, and has been associated with increased mortality in $\mathrm{CVD}^{21)}$. The most studied inflammatory marker in CVD is TNF- $\alpha^{20)}$. Increased circulating levels of TNF- $\alpha$ have been related to recurrent cardiac events following myocardial infarction and increased mortality in $\mathrm{CVD}^{21)}$.

In addition, blood levels of TNF- $\alpha$ and IL-6 are closely related with metabolic diseases including obesity and type 2 diabetes mellitus. Our results are consistent with the re- 
Table 2. The changes in glucose and pro-inflammatory cytokines

\begin{tabular}{|c|c|c|c|c|c|c|c|}
\hline Variables & Groups & & Before & After & Difference & $p$-value & Duncan \\
\hline \multirow{4}{*}{$\begin{array}{l}\text { Fasting } \\
\text { glucose } \\
(\mathrm{mg} / \mathrm{dl})\end{array}$} & Type D & Exercise & $103.92 \pm 11.06$ & $89.92 \pm 7.49$ & -14.00 & & \\
\hline & & No-Exercise & $104.08 \pm 12.54$ & $104.08 \pm 12.62$ & 0.00 & group $<0.001$ & $\mathrm{c}, \mathrm{a}<\mathrm{d}, \mathrm{b}$ \\
\hline & Not-Type D & Exercise & $95.92 \pm 8.85$ & $84.75 \pm 3.52$ & -11.17 & time 0.060 & \\
\hline & & No-Exercise & $100.73 \pm 11.96$ & $101.00 \pm 11.52$ & 0.27 & group $\times$ time 0.034 & \\
\hline \multirow{4}{*}{$\begin{array}{l}\text { TNF- } \alpha \\
(\mathrm{pg} / \mathrm{ml})\end{array}$} & Type D & Exercise & $8.10 \pm 2.12$ & $6.73 \pm 1.77$ & -16.91 & & \\
\hline & & No-Exercise & $7.97 \pm 1.98$ & $8.15 \pm 2.27$ & 2.26 & group 0.015 & $\mathrm{c}<\mathrm{d}, \mathrm{a}, \mathrm{b}$ \\
\hline & Not-Type D & Exercise & $7.04 \pm 1.70$ & $5.55 \pm 1.50$ & -21.16 & time 0.092 & \\
\hline & & No-Exercise & $7.17 \pm 1.70$ & $7.18 \pm 1.68$ & 0.14 & group $\times$ time 0.276 & \\
\hline \multirow{4}{*}{$\begin{array}{l}\text { IL-6 } \\
(\mathrm{pg} / \mathrm{ml})\end{array}$} & Type D & Exercise & $8.89 \pm 2.04$ & $7.17 \pm 1.91$ & $-19.35^{* * *}$ & & \\
\hline & & No-Exercise & $8.31 \pm 2.11$ & $8.30 \pm 2.12$ & -0.12 & group 0.014 & $\mathrm{c}<\mathrm{d}, \mathrm{a}, \mathrm{b}$ \\
\hline & Not-Type D & Exercise & $7.40 \pm 1.97$ & $5.67 \pm 2.01$ & $-23.38 * * *$ & Time 0.044 & \\
\hline & & No-Exercise & $7.23 \pm 2.02$ & $7.23 \pm 2.00$ & 0.00 & group $\times$ time 0.253 & \\
\hline
\end{tabular}

Mean \pm SD. ${ }^{* * *} \mathrm{p}<0.001 ;{ }^{*} \mathrm{p}<0.01 ;{ }^{*} \mathrm{p}<0.05$ (by paired t-test). a, Type $\mathrm{D}+$ Exercise $(\mathrm{n}=12) ; \mathrm{b}$, Type $\mathrm{D}+$ no-Exercise $(\mathrm{n}=12)$; $\mathrm{c}$, notType $\mathrm{D}+$ Exercise $(\mathrm{n}=12)$; d, not-Type $\mathrm{D}+$ no-Exercise $(\mathrm{n}=10)$

sults of previous studies ${ }^{22}$ showing that TNF- $\alpha$ and IL-6 levels of obese patients are significantly decreased by moderate walking exercise. For example, Kondo et al. ${ }^{23)}$ measured the body fat and serum cytokine levels of women who participated in an exercise program for seven months. The body fat and body mass index (BMI) of both the normal group and the obese group significantly improved and the blood levels of TNF- $\alpha$ and IL- 6 were more significantly improved in the obese group than in the normal group. Dod et al. reported ${ }^{24)}$ that the blood level of IL- 6 was significantly improved by a lifestyle modification program prescribing diet and exercise, and stress coping tips for 12 weeks.

The cytokine levels of Type D personality subjects increase by more than those of the not-Type D personality subjects when under stress ${ }^{25}$ ) and Type D subjects' precursors of inflammatory response ${ }^{9)}$, and TNF- $\alpha$ levels increase $^{5)}$. In this respect, the results of this study indicate that the reduction of TNF- $\alpha$ and IL- 6 blood levels observed after exercise may be a secondary outcome dependent on the decrease in body fat and waist circumference due to exercise, and we judge that the reduction of insulin resistance cytokine expression improves insulin sensitivity contributing to decrease in CVD risk factors.

In summary, the results of this study not only suggest the potential role of personality, they also indicate that personality may affect the established effect of exercise on cytokine activity. Type D personality was independently associated with significant immune activation, and the increase in TNF- $\alpha$ activity observed among the Type D participants.

\section{REFERENCES}

1) Kiecolt-Glaser JK, McGuire L, Robles TF, et al.: Emotions, morbidity, and mortality: new perspectives from psychoneuroimmunology. Annu Rev Psychol, 2002, 53: 83-107. [Medline] [CrossRef]

2) Torre-Amione G: Immune activation in chronic heart failure. Am J Cardiol, 2005, 95: 3C-8C, discussion 38C-40C. [Medline] [CrossRef]

3) Faris R, Purcell H, Henein MY, et al.: Clinical depression is common and significantly associated with reduced survival in patients with non-ischaemic heart failure. Eur J Heart Fail, 2002, 4: 541-551. [Medline] [CrossRef]

4) Vaccarino V, Kasl SV, Abramson J, et al.: Depressive symptoms and risk of functional decline and death in patients with heart failure. J Am Coll Cardiol, 2001, 38: 199-205. [Medline] [CrossRef]

5) Conraads VM, Jorens PG, De Clerck LS, et al.: Selective intestinal decontamination in advanced chronic heart failure: a pilot trial. Eur J Heart Fail, 2004, 6: 483-491. [Medline] [CrossRef]

6) Hansson GK: Inflammation, atherosclerosis, and coronary artery disease. N Engl J Med, 2005, 352: 1685-1695. [Medline] [CrossRef]

7) Tedgui A, Mallat Z: Cytokines in atherosclerosis: pathogenic and regulatory pathways. Physiol Rev, 2006, 86: 515-581. [Medline] [CrossRef]

8) Conraads VM, Denollet J, De Clerck LS, et al.: Type D personality is associated with increased levels of tumour necrosis factor (TNF)-alpha and TNF-alpha receptors in chronic heart failure. Int J Cardiol, 2006, 113: 34-38. [Medline] [CrossRef]

9) Denollet J, Conraads VM, Brutsaert DL, et al.: Cytokines and immune activation in systolic heart failure: the role of Type D personality. Brain Behav Immun, 2003, 17: 304-309. [Medline] [CrossRef]

10) Denollet J, Vrints CJ, Conraads VM: Comparing Type D personality and older age as correlates of tumor necrosis factor-alpha dysregulation in chronic heart failure. Brain Behav Immun, 2008, 22: 736-743. [Medline] [CrossRef]

11) Denollet J, Schiffer AA, Kwaijtaal M, et al.: Usefulness of Type D personality and kidney dysfunction as predictors of interpatient variability in inflammatory activation in chronic heart failure. Am J Cardiol, 2009, 103: 399-404. [Medline] [CrossRef]

12) Pedersen SS, Denollet J: Validity of the Type D personality construct in Danish post-MI patients and healthy controls. J Psychosom Res, 2004, 57: 265-272. [Medline] [CrossRef]

13) So WY, Choi DH: Effects of walking and resistance training on the body composition, cardiorespiratory function, physical fitness and blood profiles of middle-aged obese women. Exer Sci, 2007, 16: 85-94.

14) Arias AJ, Steinberg K, Banga A, et al.: Systematic review of the efficacy of meditation techniques as treatments for medical illness. J Altern Complement Med, 2006, 12: 817-832. [Medline] [CrossRef]

15) Korean Health Statistics: Korea National Health and Nutrition Examination Survey (KNHANES IV3). Ministry of Health and Welfare, 2009.

16) Annual report on cause of death statistics in 2009. Korea National Statistical Office. 2009. necrosis factor-alpha dysregulation in chronic heart failure. Brain, Beha Immu, 2009, 22: 736-743.

17) Kostapanos MS, Milionis HJ, Filippatos TD, et al.: A 12-week, prospective, open-label analysis of the effect of rosuvastatin on triglyceride-rich lipoprotein metabolism in patients with primary dyslipidemia. Clin Ther, 2007, 29: 1403-1414. [Medline] [CrossRef]

18) ACSM: ACSM's Guidelines for Exercise Testing and Prescription by American College of Sports Medicine, 8th ed. Lippincott Williams \& Wilkins, 2009.

19) Maachi M, Piéroni L, Bruckert E, et al.: Systemic low-grade inflammation is related to both circulating and adipose tissue TNF alpha, leptin and IL-6 levels in obese women. Inter J Obes Metab Diso, 2004, 28: 993-997. [CrossRef]

20) von Haehling S, Genth-Zotz S, Sharma R, et al.: The relationship between age and production of tumour necrosis factor-alpha in healthy volunteers 
1936 J. Phys. Ther. Sci. Vol. 26, No. 12, 2014

and patients with chronic heart failure. Int J Cardiol, 2003, 90: 197-204. [Medline] [CrossRef]

21) Deswal A, Petersen NJ, Feldman AM, et al.: Cytokines and cytokine receptors in advanced heart failure: an analysis of the cytokine database from the Vesnarinone trial (VEST). Circulation, 2001, 103: 2055-2059. [Medline] [CrossRef]

22) Azuma K, Katsukawa F, Oguchi S, et al.: Correlation between serum resistin level and adiposity in obese individuals. Obes Res, 2003, 11: 997-1001. [Medline] [CrossRef]
23) Kondo T, Kobayashi I, Murakami M: Effect of exercise on circulating adipokine levels in obese young women. Endocr J, 2006, 53: 189-195. [Medline] [CrossRef]

24) Dod HS, Bhardwaj R, Sajja V, et al.: Effect of intensive lifestyle changes on endothelial function and on inflammatory markers of atherosclerosis. Am J Cardiol, 2010, 105: 362-367. [Medline] [CrossRef]

25) Habra ME, Linden W, Anderson JC, et al.: Type D personality is related to cardiovascular and neuroendocrine reactivity to acute stress. J Psychosom Res, 2003, 55: 235-245. [Medline] [CrossRef] 